Article

\title{
Spectroscopic Study of Plasma Polymerized a-C:H Films Deposited by a Dielectric Barrier Discharge
}

\author{
Thejaswini Halethimmanahally Chandrashekaraiah ${ }^{1}$, Robert Bogdanowicz ${ }^{1,2}{ }^{,}$Eckart Rühl $^{3}$, \\ Vladimir Danilov ${ }^{1}$, Jürgen Meichsner ${ }^{1}$, Steffen Thierbach ${ }^{3}$ and Rainer Hippler ${ }^{1, *}$ \\ 1 Institut für Physik, Ernst-Moritz-Arndt-Universität Greifswald, Felix-Hausdorff-Str. 6, Greifswald 17489, \\ Germany; tch@pdx.edu (T.H.C.); rbogdan@eti.pg.gda.pl (R.B.); Vl.danilov@gmail.com (V.D.); \\ meichsner@physik.uni-greifswald.de (J.M.) \\ 2 Faculty of Electronics, Telecommunications and Informatics, Gdansk University of Technology, 11/12 G. \\ Narutowicza St., Gdansk 80-233, Poland \\ 3 Institut für Chemie und Biochemie-Physikalische und Theoretische Chemie, Freie Universität Berlin, \\ Takustr. 3, Berlin 14195, Germany; ruehl@chemie.fu-berlin.de (E.R.); thierbach@chemie.fu-berlin.de (S.T.) \\ * Correspondence: hippler@physik.uni-greifswald.de; Tel.: +49-3834-864735
}

Academic Editor: Lanxia Cheng

Received: 11 May 2016; Accepted: 6 July 2016; Published: 19 July 2016

\begin{abstract}
Plasma polymerized a-C:H thin films have been deposited on Si (100) and aluminum coated glass substrates by a dielectric barrier discharge (DBD) operated at medium pressure using $\mathrm{C}_{2} \mathrm{H}_{m} / \mathrm{Ar}(m=2,4,6)$ gas mixtures. The deposited films were characterized by Fourier transform infrared reflection absorption spectroscopy (FT-IRRAS), Raman spectroscopy, and ellipsometry. FT-IRRAS revealed the presence of $s p^{3}$ and $s p^{2} \mathrm{C}-\mathrm{H}$ stretching and $\mathrm{C}-\mathrm{H}$ bending vibrations of bonds in the films. The presence of $\mathrm{D}$ and $\mathrm{G}$ bands was confirmed by Raman spectroscopy. Thin films obtained from $\mathrm{C}_{2} \mathrm{H}_{4} / \mathrm{Ar}$ and $\mathrm{C}_{2} \mathrm{H}_{6} / \mathrm{Ar}$ gas mixtures have $\mathrm{I}_{\mathrm{D}} / \mathrm{I}_{\mathrm{G}}$ ratios of 0.45 and 0.3 , respectively. The refractive indices were 2.8 and 3.1 for $\mathrm{C}_{2} \mathrm{H}_{4} / \mathrm{Ar}$ and $\mathrm{C}_{2} \mathrm{H}_{6} / \mathrm{Ar}$ films, respectively, at a photon energy of $2 \mathrm{eV}$.
\end{abstract}

Keywords: dielectric barrier discharge (DBD); thin film deposition; a-C:H films; atmospheric pressure; hydrocarbon plasma

PACS: 78.20.-e; 78.30.-j; 78.66.Qn; 81.15.Gh

\section{Introduction}

In recent years, plasma deposited amorphous hydrogenated carbon (a-C:H) films have been widely used in scientific and industrial fields due to their excellent mechanical, chemical, tribological, optical, and electronic [1-5] properties. Hydrogenated carbon films are frequently classified into four classes: polymer-like films with the highest hydrogen content of up to $50 \%$ and up to $60 \%$ of hydrogen-terminated $s p^{3}$ bonds, diamond-like films with an intermediate $\mathrm{H}$ content (about $30 \%$ ) and a large fraction of $\mathrm{C}-\mathrm{C} s p^{3}$ bonds, hydrogenated tetrahedral carbon films (ta-C:H) with a typically hydrogen content of $25 \%$ and the highest $s p^{3}$ content of about $70 \%$, and graphite-like films with low hydrogen $(<20 \%)$ but large $s p^{2}$ contents [6]. Due to these properties, hydrogenated carbon films can be used for super-hard materials [1], biomaterials [7], wear-resistant coatings [8], optical coatings [9], field enhanced conductors [10], smart polymer and biopolymer films [11,12], and hydrogen storage devices [13]. Film characteristics can be suitably tailored for particular applications employing different deposition techniques and precursor gas mixtures, e.g., chemical vapor deposition (CVD) [14], sputtering [15], plasma enhanced chemical vapor deposition (PECVD) [16], and pulsed laser deposition (PLD) [17]. 
In the current study, we have used a dielectric barrier discharge (DBD) for the preparation of a-C:H thin films [18-20]. The advantage of using DBD is that this technique does not involve physical sputtering resulting in a long life time of the deposition device and that a high electron density $\left(10^{11} \mathrm{~cm}^{-3}\right)$ can be achieved during film deposition. DBDs when operated at atmospheric pressure do not require an expensive vacuum system which saves costs and allows for an easy handling of deposited films during and after deposition. A certain disadvantage is the narrow discharge gap of typically $0.1 \mathrm{~cm}$ or less [21]. In this work we have employed a DBD at a medium pressure of 300 mbar for deposition of amorphous hydrogenated carbon films. It is well known that the choice of a suitable hydrocarbon precursor can result in different film properties. The use of $\mathrm{C}_{2} \mathrm{H}_{m} / \mathrm{Ar}(m=2,4,6)$ gas mixtures in the present work extends previous investigations employing $\mathrm{CH}_{4}$ precursors and allows for a tailoring of film properties into the desired direction. A plasma chemical characterization of the employed DBD based on mass spectrometry and infrared spectroscopy has been published recently [22]. The deposited films were characterized by Fourier transform infrared reflection absorption spectroscopy (FT-IRRAS), Raman spectroscopy, and spectroscopic ellipsometry (SE).

\section{Experimental}

The experimental setup has been described in detail elsewhere [22-26]. Briefly, it consists of a plasma chamber with inner dimensions for height, length, and width of $12.3 \mathrm{~cm}, 18.0 \mathrm{~cm}$, and $15.0 \mathrm{~cm}$, respectively. The two discharge electrodes, each with a length of $8.3 \mathrm{~cm}$, a width of $3.3 \mathrm{~cm}$, and a thickness of $0.15 \mathrm{~cm}$, are made of stainless steel and embedded in a rectangular shaped poly-methyl methacrylate (PMMA) case. Both electrodes are covered by dielectrics, the upper powered electrode was covered by $\mathrm{Al}_{2} \mathrm{O}_{3}(\varepsilon \approx 10)$ and the lower grounded electrode was covered by glass $(\varepsilon \approx 3.8)$. The two electrodes are separated $2 \mathrm{~mm}$ or $1.5 \mathrm{~mm}$ by a PTFE spacer. The substrate was placed on the glass electrode for thin film deposition. Two different kinds of substrate materials were used for the deposition experiments: aluminum coated glass substrates for FT-IRRAS analysis with dimensions of $6 \times 2 \mathrm{~cm}^{2}$ and silicon (100) wafers with dimensions of $2 \times 3 \mathrm{~cm}^{2}$ for Raman spectroscopy and ellipsometric studies. A highly reflecting metallic coating of about $190 \mathrm{~nm}$ thickness on the glass substrate was prepared by thermal evaporation of aluminum under vacuum conditions.

The plasma chamber was pumped by a membrane pump down to about $10 \mathrm{mbar}$. The pressure was monitored using a mechanical pressure gauge connected to the chamber. The pressure inside the chamber was controlled by two gas flow controllers for the hydrocarbon and argon gases and by a needle valve between the chamber and the membrane pump. For all experiments a hydrocarbon-to-argon ratio of 1:2 was used. The chamber was filled with hydrocarbon and argon gas to a partial pressure of 100 mbar and 200 mbar, respectively, prior to the plasma operation. Pump and gas flow were switched off once the chamber was filled.

The high voltage power supply consists of a frequency generator delivering a sinusoidal output that is fed into an audio amplifier. The amplifier can operate up to $500 \mathrm{~W}$; its output is fed into a spark plug transformer. The experiments were performed at voltage amplitudes up to $5.7 \mathrm{kV}$ and at a frequency of $5.5 \mathrm{kHz}$. In order to measure the discharge power a small capacitor $(C=10 \mathrm{nF})$ is placed in series between the lower electrode and ground. The voltages applied to the powered and grounded electrode, respectively, are measured with a high voltage probe and serve as $x$ and $y$ input of a digital oscilloscope. The discharge power is calculated from the resulting Lissajous figures using the standard method based on the area enclosed by the curve and was kept constant $(4 \mathrm{~W})$ during the experiments.

\subsection{Fourier Transform Infrared Reflection Absorption Spectroscopy (FT-IRRAS)}

The functional groups present in the films deposited on aluminum coated glass substrates were evaluated by Fourier transform infrared reflection absorption spectroscopy (BRUKER, VERTEX 80V, Karlsruhe, Germany). Prior to the experiments, the sample compartment was evacuated to 2 mbar to reduce absorption of water vapor and $\mathrm{CO}_{2}$. The spectra were recorded in the range from 4000 
to $500 \mathrm{~cm}^{-1}$ with a spectral resolution of $0.7 \mathrm{~cm}^{-1}$. Each spectrum was the average of 32 scans. A background spectrum was taken from each substrate prior to the deposition of a-C:H films.

\subsection{Raman Spectroscopy}

Raman spectra for the films were measured with a Raman microscope (Olympus BX 41 linked to a DILOR XY-800 from HORIBA Jobin-Yvon, Bensheim, Germany) using the second harmonics of a Nd:YAG laser (532 nm) as a light source and a CCD-camera (Synapse from HORIBA Jobin-Yvon). The samples were placed on a turntable under the microscope to provide a large sampling area for suitable averaging as well as heat dissipation. To decrease further the local radiation intensity, the measurements were done out of focus at a sample distance of $125 \mu \mathrm{m}$ using an objective with 50-fold magnification. The resulting laser spot was about $50 \mu \mathrm{m}$ in diameter. The power of the laser beam was adjusted in the range of 5-20 $\mathrm{mW}$ in order to avoid sample damage as well as fluorescence.

\subsection{Spectroscopic Ellipsometry (SE)}

Spectroscopic ellipsometry investigations were carried out with a phase modulated ellipsometer Jobin-Yvon UVISEL (HORIBA Jobin-Yvon). The investigated photon energy region was 1.5-4.5 eV with an energy step of $0.05 \mathrm{eV}$. The experiments were carried out at room temperature using an angle of incidence fixed at $70^{\circ}$ and the compensator was set to $45^{\circ}$. The incidence angle of $70^{\circ}$ resulted from Brewster's angle of the Si (100) wafer substrate. DeltaPsi software (v. 2.6, HORIBA Jobin-Yvon, Bensheim, Germany) was employed to determine the spectral distributions of the refractive index $n(\lambda)$ and the extinction coefficient $k(\lambda)$ of amorphous carbon films.

\section{Results and Discussion}

The physical and chemical properties of a-C:H films obtained from different $\mathrm{C}_{2} \mathrm{H}_{m} / \operatorname{Ar}(m=2,4,6)$ gas mixtures are discussed in this section. A photograph displaying the deposited a-C:H films on a glass substrate for different precursor gases is presented in Figure 1. Films deposited with different precursor gases show different colors. Deposited thin films show transparent, yellow, and brown color for $\mathrm{C}_{2} \mathrm{H}_{6} / \mathrm{Ar}, \mathrm{C}_{2} \mathrm{H}_{4} / \mathrm{Ar}$ and $\mathrm{C}_{2} \mathrm{H}_{2} / \mathrm{Ar}$ gas mixtures, respectively. $\mathrm{C}_{2} \mathrm{H}_{4} / \mathrm{Ar}$ and $\mathrm{C}_{2} \mathrm{H}_{6} / \mathrm{Ar}$ films were sticky in nature; the $\mathrm{C}_{2} \mathrm{H}_{2} / \mathrm{Ar}$ film had small particles (of $\mu \mathrm{m}$ size) on its surface. The thickness of the film was in the order of several micrometers after $5 \mathrm{~h}$ of deposition.

The deposition rates were estimated from the additional mass deposited on the glass substrate $\left(7.4 \times 2.2 \mathrm{~cm}^{2}\right)$ which were weighted on a micro balance before and after deposition. Typical deposition rates were in the range $0.08-0.3 \mu \mathrm{g} /\left(\mathrm{s} \cdot \mathrm{cm}^{2}\right)$ (Table 1 ).

Table 1. Mean deposition rates for different precursor molecules.

\begin{tabular}{cc}
\hline Gas Mixture & Deposition Rate in $\mathbf{1 0}^{-\mathbf{5}} \mathbf{~} \mathbf{k g} /\left(\mathbf{s} \cdot \mathbf{~ m}^{\mathbf{2}}\right)$ \\
\hline $\mathrm{C}_{2} \mathrm{H}_{6} / \mathrm{Ar}$ & 0.08 \\
$\mathrm{C}_{2} \mathrm{H}_{4} / \mathrm{Ar}$ & 0.18 \\
$\mathrm{C}_{2} \mathrm{H}_{2} / \mathrm{Ar}$ & 0.28 \\
\hline
\end{tabular}

The coloring effect (Figure 1) is the results of optical absorption introduced by $s p$ and $s p^{2}$ hybridized phases in agreement with our FTIR results, see below. The unsaturated hydrocarbon precursors provide a high level of unsaturated bonding structures of the deposited films (see below). As the amount of $s p$ and $s p^{2}$ bonded carbon increases, the bonding structure changes. The density of $\pi$ electrons increases and thus the absorbance of films in the visible range increases. That fact is also proved by an increase of $I_{\mathrm{D}} / I_{\mathrm{G}}$ ratio as revealed by Raman spectroscopy. Moreover, the thickness of the $\mathrm{C}_{2} \mathrm{H}_{4}$ / Ar sample estimated by SE is about two times higher than for $\mathrm{C}_{2} \mathrm{H}_{6} / \mathrm{Ar}$. This fact enhances coloring effects as it causes a higher absorbance. Similar brown coloring effects have been observed and reported by Shirakura et al. of diamond-like carbon thin films deposited at PET bottles [27]. 


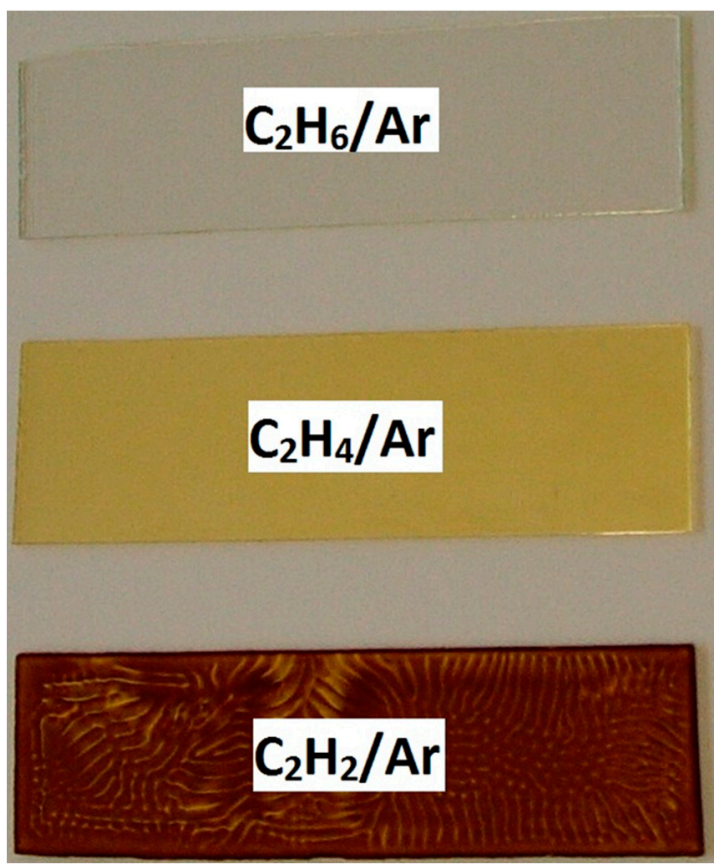

Figure 1. Photographs of a-C:H films deposited on glass substrates in a dielectric barrier discharge (DBD) with different precursor gases $\mathrm{C}_{2} \mathrm{H}_{m} / \mathrm{Ar}(m=2,4,6)$.

The investigated hydrocarbons are characterized by different hydrogen contents and, in the case of acetylene, by a $\mathrm{C} \equiv \mathrm{C}$ triple bond. The degree of cross-linking, the hydrogen content, and the fraction of $s p^{2}$ and $s p^{3}$ bonds are also determined by the plasma conditions, for example, power density and the local ion bombardment during film growth. In generally, one can distinguish between a power-deficit regime when sufficient precursor molecules are present and a monomer-deficit regime at a large discharge power when precursor molecules are completely consumed in the deposition process. Film deposition with $\mathrm{C}_{2} \mathrm{H}_{6}, \mathrm{C}_{2} \mathrm{H}_{4}$, and $\mathrm{C}_{2} \mathrm{H}_{2}$ precursors with $\mathrm{C}$-to- $\mathrm{H}$ ratios of $0.33,0.5$, and 1 results in cross-linked a-C:H films which show an increasing absorption in the visible and ultraviolet range as is expected from the raising carbon (lower hydrogen) content in the precursor.

\subsection{Fourier Transform Infrared Reflection Absorption Spectroscopy (FT-IRRAS)}

FTIR spectra of a-C:H films deposited on aluminum-coated glass substrates using $\mathrm{C}_{2} \mathrm{H}_{m} / \mathrm{Ar}$ $(m=2,4,6)$ gas mixtures at 300 mbar gas pressure with a gas ratio of 1:2 (Figure 2) were measured. The measured spectra can be subdivided into five spectral regions I, II, III, IV, and V corresponding to the intervals $3200-3600 \mathrm{~cm}^{-1}, 2700-3100 \mathrm{~cm}^{-1}, 2040-2290 \mathrm{~cm}^{-1}, 1550-1850 \mathrm{~cm}^{-1}$, and $600-1550 \mathrm{~cm}^{-1}$, respectively. In general, the $\mathrm{C}_{2} \mathrm{H}_{4} / \mathrm{Ar}$ and $\mathrm{C}_{2} \mathrm{H}_{6} / \mathrm{Ar}$ films display a rather similar absorbance while significant differences compared to the $\mathrm{C}_{2} \mathrm{H}_{2}$ / Ar film are noticeable.

Region I (3200-3600 $\mathrm{cm}^{-1}$ ): The broad band arises due to hydroxyl groups. There are two reasons for the presence of oxygen and hydroxyl groups. The first is associated with atmospheric moisture [28] which is an impurity caused during film transfer from DBD chamber to FTIR chamber. We tried to avoid this by quickly moving the sample to the FTIR chamber. Reducing the impurity level to zero in this process was highly impossible, however. The second reason which comes to mind is the surface of electrodes which by itself contain oxygen which could be released through chemical reactions during plasma operation. Other functional groups associated with oxygen are observed in regions IV and V.

Region II (2700-3100 $\mathrm{cm}^{-1}$ ) shows the strongest absorbance; it is related to $s p^{2}$ and $s p^{3} \mathrm{CH}_{\mathrm{x}}$ stretching vibrations [26,29-31]. Polymer-like films exhibit about $40 \%-60 \%$ of $s p^{2}$ and $s p^{3}$ hybridized $\mathrm{C}-\mathrm{H}$ bonds in their structure. The magnification of the region from 2700 to $3100 \mathrm{~cm}^{-1}$ (Figure $2 \mathrm{~b}$ ) shows the presence of different modes of $\mathrm{C}-\mathrm{H}$ vibrations in all three films. The bands at $2872 \mathrm{~cm}^{-1}$, 
$2930 \mathrm{~cm}^{-1}$ and $2959 \mathrm{~cm}^{-1}$ are related to $s p^{3} \mathrm{CH}_{3}$ symmetric, superimposing of $s p^{3} \mathrm{CH}_{2}$ asymmetric and $s p^{3} \mathrm{C}-\mathrm{H}$ mode, and $s p^{3} \mathrm{CH}_{3}$ asymmetric $\mathrm{C}-\mathrm{H}$ vibrations, respectively [26,29-31]. The relative absorbance of these bands is much higher than for DLC films [31-34]. The $\mathrm{C}_{2} \mathrm{H}_{6} / \mathrm{Ar}$ film shows the strongest absorption near $2900 \mathrm{~cm}^{-1}$ and consequently the highest $s p^{3} \mathrm{CH}_{3}$ configuration compared to the other two films. All these bands are characteristic of a hydrogen-rich carbon film. From Table 2, the largest FTIR absorbance can be found in this region for all films.
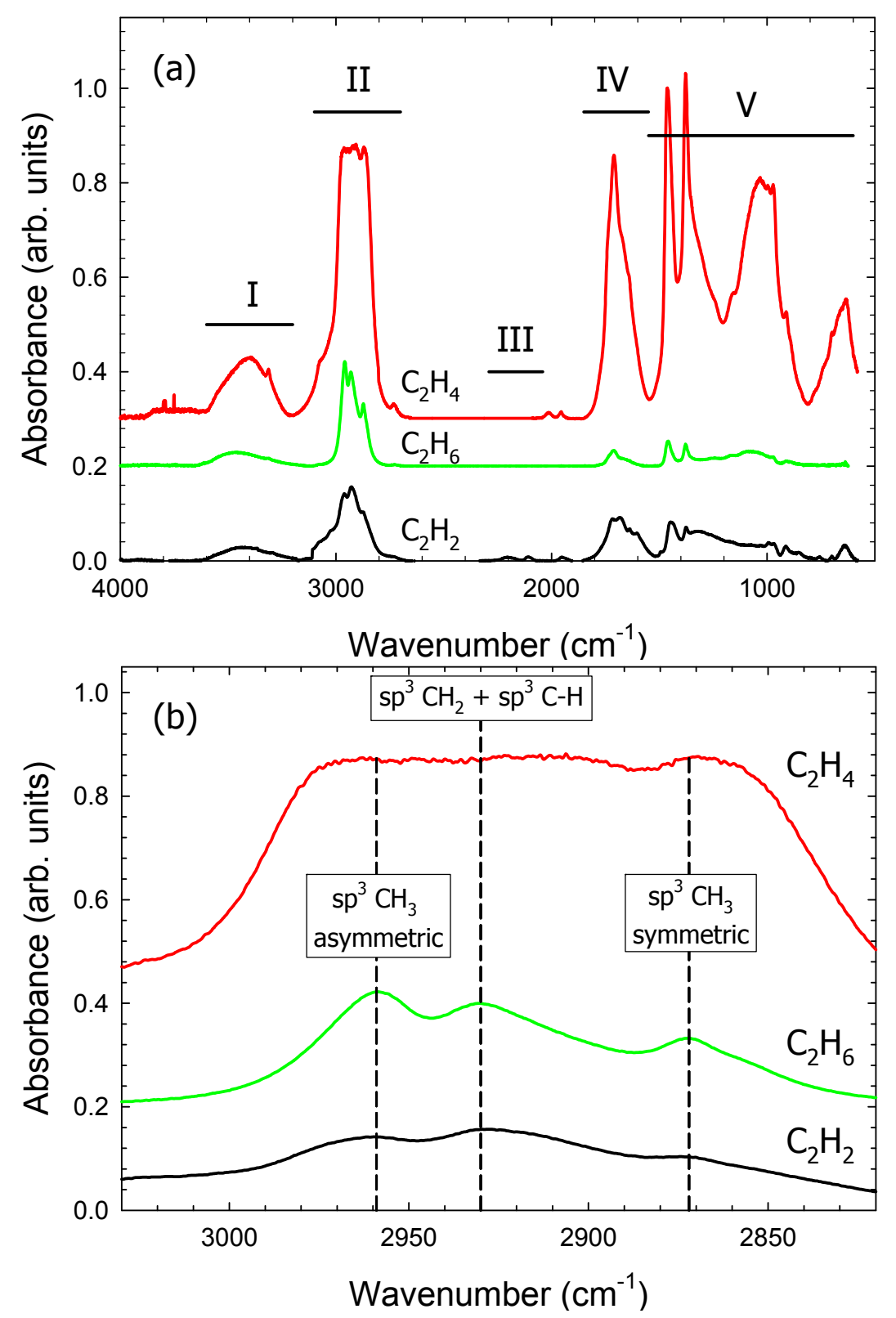

Figure 2. (a) FTIR spectra of a-C:H films obtained from $\mathrm{C}_{2} \mathrm{H}_{m} / \mathrm{Ar}(m=2,4,6)$ gas mixture, (gas pressure $=300 \mathrm{mbar}$, gas ratio $=1: 2$, power $=4 \mathrm{~W}$ ). To ease comparison, the data obtained with $\mathrm{C}_{2} \mathrm{H}_{6} / \mathrm{Ar}$ and $\mathrm{C}_{2} \mathrm{H}_{4} / \mathrm{Ar}$ are shifted upwards by 0.2 and 0.3 , respectively; (b) Magnification of the FTIR region 3030-2820 $\mathrm{cm}^{-1}$. For comparison, the data obtained with $\mathrm{C}_{2} \mathrm{H}_{6} / \mathrm{Ar}$ and $\mathrm{C}_{2} \mathrm{H}_{4} / \mathrm{Ar}$ are shifted upwards.

Region III (2040-2290 $\mathrm{cm}^{-1}$ ) provides the absorbance of chemical bonds containing $\mathrm{C} \equiv \mathrm{C}$ functional groups. Thin films deposited from $\mathrm{C}_{2} \mathrm{H}_{4} / \mathrm{Ar}$ and $\mathrm{C}_{2} \mathrm{H}_{6} / \mathrm{Ar}$ gas mixtures do not show any absorption in this region. The $\mathrm{C}_{2} \mathrm{H}_{2} / \mathrm{Ar}$ film shows a weak doublet at 2200 and $2100 \mathrm{~cm}^{-1}$ which 
is related to stretching of $\mathrm{C} \equiv \mathrm{C}$ bonds. Thin films deposited under the same experimental parameters from $\mathrm{C}_{2} \mathrm{H}_{2} / \mathrm{N}_{2}, \mathrm{C}_{2} \mathrm{H}_{4} / \mathrm{N}_{2}$ and $\mathrm{C}_{2} \mathrm{H}_{6} / \mathrm{N}_{2}$ gas mixtures shows absorbance in this region which, however, is largely due to nitrile and isonitrile groups [35].

Region IV (1550-1850 $\left.\mathrm{cm}^{-1}\right)$ is associated with $\mathrm{C}=\mathrm{C}$ and $\mathrm{C}=\mathrm{O}$ stretching vibrations [26,30] and $\mathrm{C}-\mathrm{H}$ bending vibrations. The broad band at $1700 \mathrm{~cm}^{-1}$ is related to $\mathrm{C}=\mathrm{C}$ and $\mathrm{C}=\mathrm{O}$ stretching vibrations. The intensity of this band is smallest for the $\mathrm{C}_{2} \mathrm{H}_{6} / \mathrm{Ar}$ film.

Table 2. Relative absorbance of regions I, II, III, IV, and V (with respect to the integral absorbance of the measured spectral ranges).

\begin{tabular}{ccccc}
\hline \multirow{2}{*}{ Region } & \multirow{2}{*}{ Wavenumber $\left(\mathbf{c m}^{-\mathbf{1}}\right)$} & \multicolumn{3}{c}{ Relative Absorbance } \\
\cline { 3 - 5 } & & $\mathbf{C}_{\mathbf{2}} \mathbf{H}_{\mathbf{2}}$ & $\mathbf{C}_{\mathbf{2}} \mathbf{H}_{\mathbf{4}}$ & $\mathbf{C}_{\mathbf{2}} \mathbf{H}_{\mathbf{6}}$ \\
\hline I & $3200-3600$ & 0.11 & 0.09 & 0.19 \\
II & $2700-3100$ & 0.40 & 0.35 & 0.58 \\
III & $2040-2290$ & 0.01 & 0.00 & 0.00 \\
IV & $1550-1850$ & 0.22 & 0.20 & 0.07 \\
V & $1200-1550$ & 0.26 & 0.36 & 0.15 \\
\hline
\end{tabular}

Region V: Bands at $1459 \mathrm{~cm}^{-1}$ and $1370 \mathrm{~cm}^{-1}$ are related to $\mathrm{C}-\mathrm{H}_{\mathrm{x}}$ bending vibrations [26,30]. The broad band at $1024 \mathrm{~cm}^{-1}$ is due to $\mathrm{C}-\mathrm{O}$ stretching and $\mathrm{O}-\mathrm{H}$ deformation vibrations. The band at $640 \mathrm{~cm}^{-1}$ is from the benzene ring which is related to out-of-plane $\mathrm{C}-\mathrm{H}$ deformations. All three films show the same functional groups but with different absorbances.

The relative absorbance of the five regions (with respect to the integral absorbance of the measured spectral range) is shown in Table 2. Distinct differences are noted. For example, region II (2700-3100 $\mathrm{cm}^{-1}$ ) shows a pronounced absorbance in all three spectra; the region dominates in the films deposited with $\mathrm{C}_{2} \mathrm{H}_{2}$ and $\mathrm{C}_{2} \mathrm{H}_{6}$ precursors and is equally strong as region $\mathrm{V}\left(1200-1550 \mathrm{~cm}^{-1}\right)$ of the film deposited with $\mathrm{C}_{2} \mathrm{H}_{4}$. The strong absorbance in this region confirms the films contain a significant amount of hydrogen. Region III is the weakest of all regions and only absorbing in the film from the $\mathrm{C}_{2} \mathrm{H}_{2}$ precursor. Region IV is fairly strong in the $\mathrm{C}_{2} \mathrm{H}_{2}$ and $\mathrm{C}_{2} \mathrm{H}_{4}$ films but much weaker in the $\mathrm{C}_{2} \mathrm{H}_{6}$ film.

A quantitative analysis of the molecular structure by infrared (FTIR) and Raman spectroscopy is difficult to perform and was not attempted here. In particular, due to different and largely unknown cross sections the peak absorbance is not a measure for the content of specific molecular groups. The absorbance is additionally influenced by the non-uniform molecular surrounding due to crosslinking and interactions between molecular groups. As a consequence, the center peak intensity decreases and the absorption bands become broadened.

\subsection{Raman Spectroscopy}

Raman spectra for $\mathrm{C}_{2} \mathrm{H}_{4} / \mathrm{Ar}$ and $\mathrm{C}_{2} \mathrm{H}_{6} / \mathrm{Ar}$ films are displayed in Figure 3. Raman spectroscopy is a standard nondestructive tool for the characterization of crystalline, non-crystalline, and amorphous carbon. Raman spectra for $\mathrm{C}_{2} \mathrm{H}_{4} / \mathrm{Ar}$ and $\mathrm{C}_{2} \mathrm{H}_{6} / \mathrm{Ar}$ films show similar characteristics. Generally, Raman spectra of disordered graphite show two sharp modes, so-called $G$ and D peaks which we observe around $1640 \mathrm{~cm}^{-1}$ (G-peak) and $1355 \mathrm{~cm}^{-1}$ (D-peak); the G-peak $\left(I_{\mathrm{G}}\right)$ is frequently assigned to the $E_{2 \mathrm{~g}}$ symmetric vibration mode of graphite layers in the film [36,37]. The D and G peaks are both related to $s p^{2}$ bonds. The $\mathrm{G}$ peak comes from the stretching vibrations of $s p^{2}$ bonds either from $\mathrm{C}=\mathrm{C}$ chains or aromatic rings while the $\mathrm{D}$ peak corresponds to the breathing mode of $s p^{2}$ bonds only in rings [28]. The evaluated $I_{D} / I_{G}$ intensity ratio was about 0.45 and 0.3 for the $\mathrm{C}_{2} \mathrm{H}_{4} / \mathrm{Ar}$ and the $\mathrm{C}_{2} \mathrm{H}_{6} / \mathrm{Ar}$ film, respectively. The small $I_{D} / I_{G}$ intensity ratio shows that $\mathrm{C}_{2} \mathrm{H}_{4} / \mathrm{Ar}$ and $\mathrm{C}_{2} \mathrm{H}_{6} / \mathrm{Ar}$ films contain a significant amount of hydrogen and have a large fraction of $s p^{2}$ hybridized bonding. In addition we observe a sharp peak at $1460 \mathrm{~cm}^{-1}$ which is assigned to the to a $\mathrm{C} 5 \mathrm{Ag}_{(2)}$ pentagonal pinch mode in trans-polyacetylene [6,38]. Polyacetylene consists of long chains of $\mathrm{CH}$ groups with alternating single 
and double bonds between the carbon atoms. The amount of polyacetylene is believed to be small, however, as it has a large Raman cross section [6].

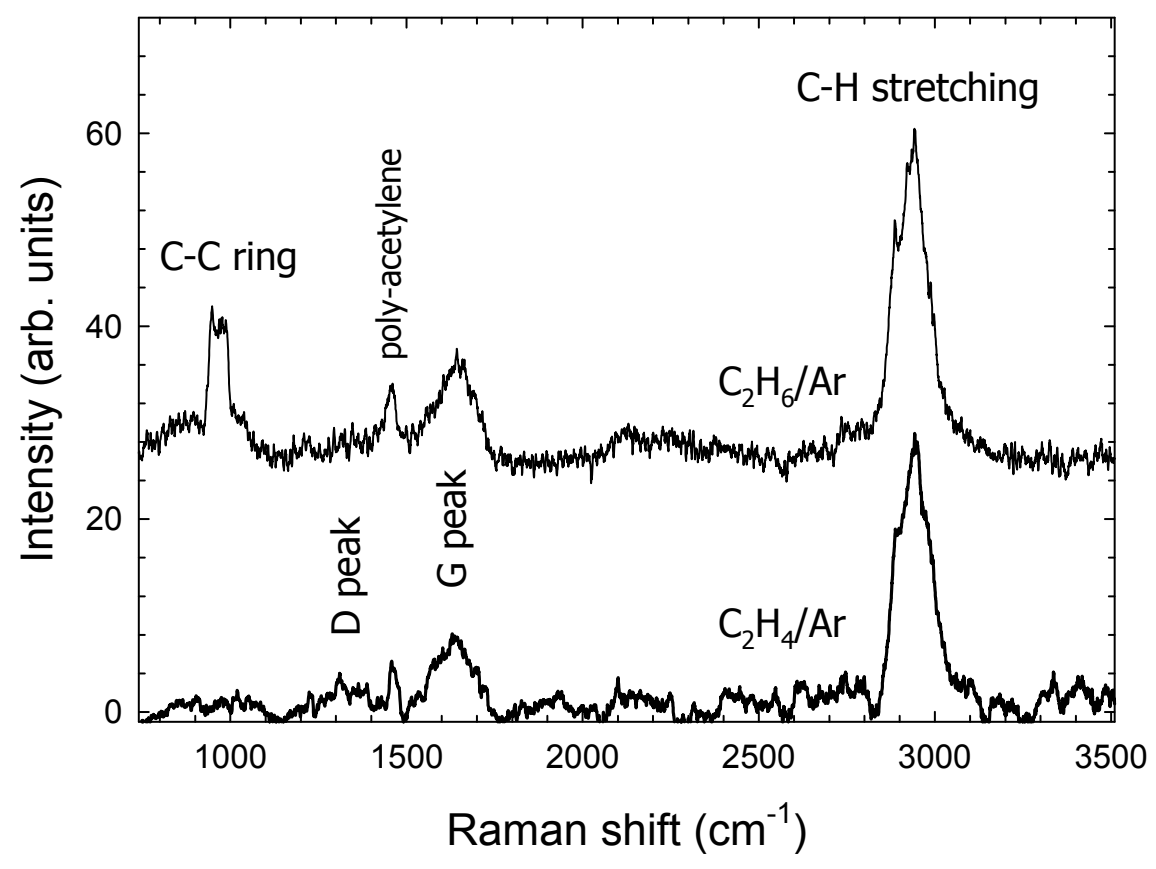

Figure 3. Raman spectra of a-C:H films obtained from $\mathrm{C}_{2} \mathrm{H}_{m} / \mathrm{Ar}(m=4,6)$ gas mixtures, (gas pressure $p=300$ mbar, gas ratio 1:2, power $p=4 \mathrm{~W}$ ).

Almost identical $\mathrm{I}_{\mathrm{D}} / \mathrm{I}_{\mathrm{G}}$ ratios have been observed by Olivera et al. [39] for films that were prepared using PECVD. The band at $2937 \mathrm{~cm}^{-1}$ is related to $\mathrm{C}-\mathrm{H}$ stretching vibrations which are also observed with FTIR spectroscopy. No Raman measurements were carried out for the $\mathrm{C}_{2} \mathrm{H}_{2} / \mathrm{Ar}$ film due to poor film quality. We do expect a larger $I_{\mathrm{D}} / I_{\mathrm{G}}$ ratio caused by a smaller hydrogen content for the $\mathrm{C}_{2} \mathrm{H}_{2} / \mathrm{Ar}$ film $[6,38]$.

\subsection{Ellipsometry}

In this study, fitting calculations were based on a four-phase optical model (ambient/amorphous carbon $/ \mathrm{SiO}_{2} / \mathrm{Si}$-wafer). Amorphous carbon was assumed as an isotropic, homogeneous material and its dispersion was simulated by the Tauc-Lorentz oscillator (TL) model. We used a recently proposed dispersion model for amorphous semiconductors by Gioti et al. and Logothetidis et al. [40,41]. The TL model is a wide-spread used approach for the description of dispersion of the optical properties of $\mathrm{a}-\mathrm{C}, \mathrm{a}-\mathrm{C}: \mathrm{H}$ and layers deposited by DBD discharge. This model is the combination of the Tauc joint density of states [40] and the quantum mechanical Lorentz oscillator model [42]. TL model fits to the dielectric functions of amorphous material class, which exhibit a peculiarity due to the presence of two separated contribution of inter-band electronic transition related to $s p^{2}$ and $s p^{3}$ bonded carbon [43]. The appropriate parameters of TL model were applied for the analyzed layer considering different film structure which was derived from Raman results.

Moreover, the dispersion of $\mathrm{Si}(100)$ wafer covered by a $2.2 \mathrm{~nm}$ thin $\mathrm{SiO}_{2}$ native oxide films were taken from database [44]. The assumed optical model was fitted to the experimental data by a non-linear Levenberg-Marquardt regression [45] using mean-square error minimization. The fitting procedure described above gives accurate values of film thicknesses as well as variation of the refractive index and extinction coefficient versus wavelength. Spectral variations of $n(\lambda)$ and $k(\lambda)$ of samples are presented in Figure 4. $n(\lambda)$ and $k(\lambda)$ appear like quantities connected by the Kramers-Kronig relations [45]. This means that $n(\lambda)$ shows an inflection point at a wavelength where $k(\lambda)$ exhibits maximum values in the visible wavelength regime (at about $2.6 \mathrm{eV}$ or $477 \mathrm{~nm}$ ). Refractive indices 
decrease from low to high energies. They correspond to 2.81 and 3.08 at $2 \mathrm{eV}(633 \mathrm{~nm})$, respectively, for $\mathrm{C}_{2} \mathrm{H}_{6} / \mathrm{Ar}$ and $\mathrm{C}_{2} \mathrm{H}_{4} /$ Ar samples.

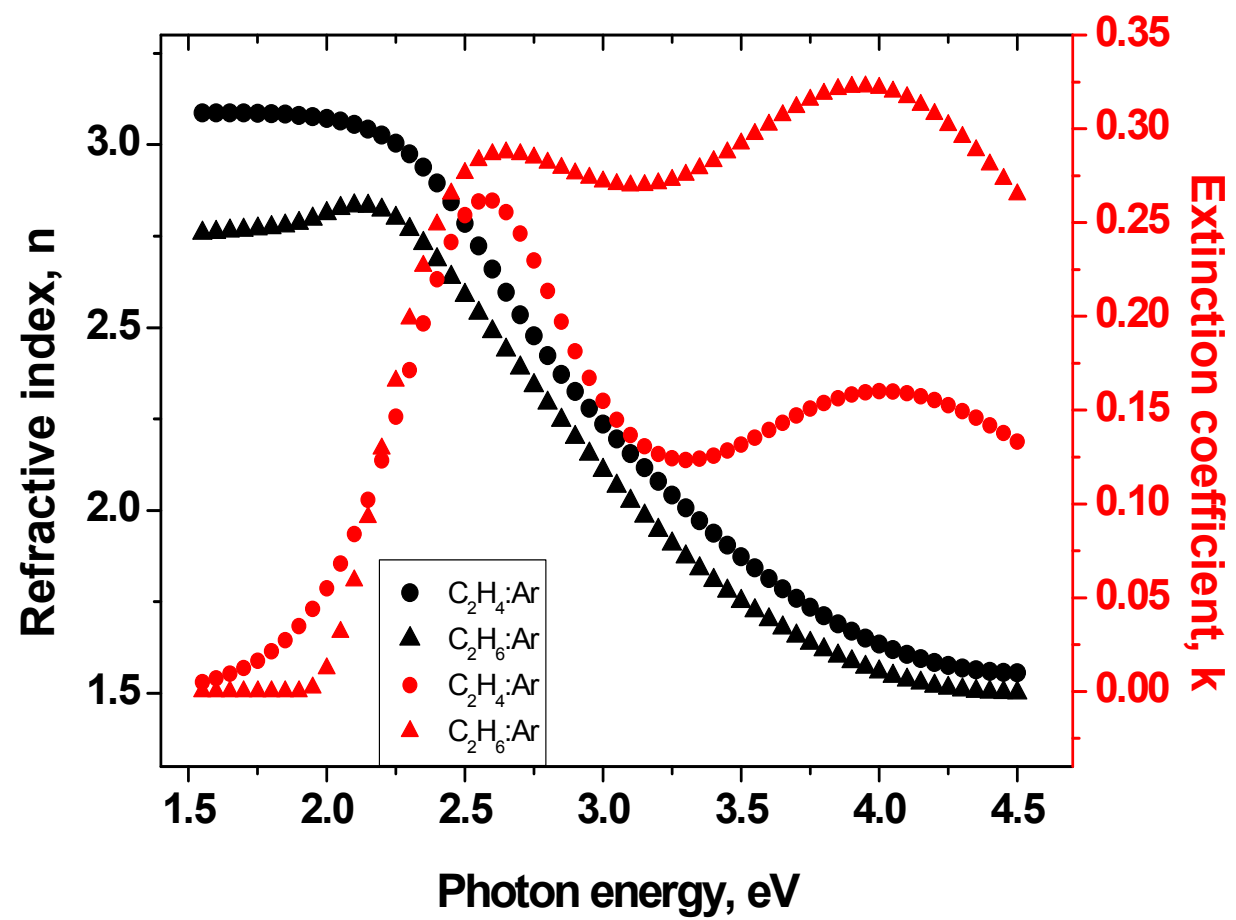

Figure 4. Wavelength-dependence of the optical constants $n(\lambda)$ and $k(\lambda)$ for the films prepared with $\mathrm{C}_{2} \mathrm{H}_{4} / \mathrm{Ar}$ and $\mathrm{C}_{2} \mathrm{H}_{6} /$ Ar gas mixtures.

These values are reasonable higher than optical constants of a-C:H thin $\mathrm{rf}$ PE CVD films $(n \approx 1.7-2.2)$ grown in a $\mathrm{CH}_{4} / \mathrm{H}_{2}$ gas mixture [46,47] or a-C:H thin dc PE CVD films $(n \approx 2.2)$ deposited using acetylene precursors [48]. It is worth noting that the rf sputtered a-C films studied by Gioti et al. [42] also show refractive indices of 2.2-3.0 in the visible wavelength range. A comparable refractive index $(n \approx 2.6-2.8)$ was obtained for hydrogenated carbon films deposited in an $\mathrm{Ar} / \mathrm{H}_{2}$ gas mixture using an expanding thermal plasma CVD process [49] or a filtered cathodic vacuum arc (FCVA) [50].

The maximum extinction coefficient of the $\mathrm{C}_{2} \mathrm{H}_{6} / \mathrm{Ar}$ sample (0.32) occurs at $4 \mathrm{eV}$. It comes from electronic transitions and causes absorption in the UV. It is higher than the highest $k(\lambda)$ value of the $\mathrm{C}_{2} \mathrm{H}_{4}$ / Ar sample (0.27) because this sample contains more $s p^{2}$ hybridized phase. Deposition using $\mathrm{C}_{2} \mathrm{H}_{6}$ decreases the amount of $s p^{3}$ hybridized phase. It could be also observed as a lower $I_{\mathrm{D}} / I_{\mathrm{G}}$ ratio extracted from Raman spectroscopy results. Generally, the spectral variation of the extinction coefficient exhibits smaller values for $\mathrm{C}_{2} \mathrm{H}_{4} / \mathrm{Ar}$ samples compared to $\mathrm{C}_{2} \mathrm{H}_{6} / \mathrm{Ar}$ films. This yields values close to zero below $2 \mathrm{eV}$ photon energy, which is indicated as a high film transparency in the visible wavelength regime and is typical for DLC and a-C:H films (Figure 5). The optical band gap, calculated by the Tauc relationship [51], exhibits slightly higher values for $\mathrm{C}_{2} \mathrm{H}_{6} / \mathrm{Ar}$ sample (see Table 3). However, the obtained $E_{\mathrm{og}}$ values are typical for carbon containing $s p^{3}$ hybridized fractions.

Table 3. Parameters of amorphous carbon samples obtained from spectroscopic ellipsometry and Raman spectroscopy.

\begin{tabular}{cccc}
\hline Sample & $\boldsymbol{n}\left(\mathbf{~} \mathbf{2}_{\mathbf{e V})}\right.$ & $\boldsymbol{E}_{\mathbf{o g}}(\mathbf{e V})$ & $\boldsymbol{I}_{\mathbf{D}} / \mathbf{I}_{\mathrm{G}}$ Ratio \\
\hline $\mathrm{C}_{2} \mathrm{H}_{4} / \mathrm{Ar}$ & 3.07 & 1.75 & 0.45 \\
$\mathrm{C}_{2} \mathrm{H}_{6} / \mathrm{Ar}$ & 2.81 & 1.91 & 0.3 \\
\hline
\end{tabular}


The thickness of the $\mathrm{C}_{2} \mathrm{H}_{4} / \mathrm{Ar}$ sample is about two times higher than for $\mathrm{C}_{2} \mathrm{H}_{6} / \mathrm{Ar}$. Moreover, this difference also comes from lower activity of the $\mathrm{C}_{2} \mathrm{H}_{6}$ precursor in layer nucleation concerned with higher level of saturation of the carbon bonds in this hydrocarbon. The type of hydrocarbon also influences carbon incorporation into the layer and types of bonding hybridization. Ellipsometry measurement for $\mathrm{C}_{2} \mathrm{H}_{2}$ / Ar films was not successful since the deposited film contained too many small micro-particles on its surface.

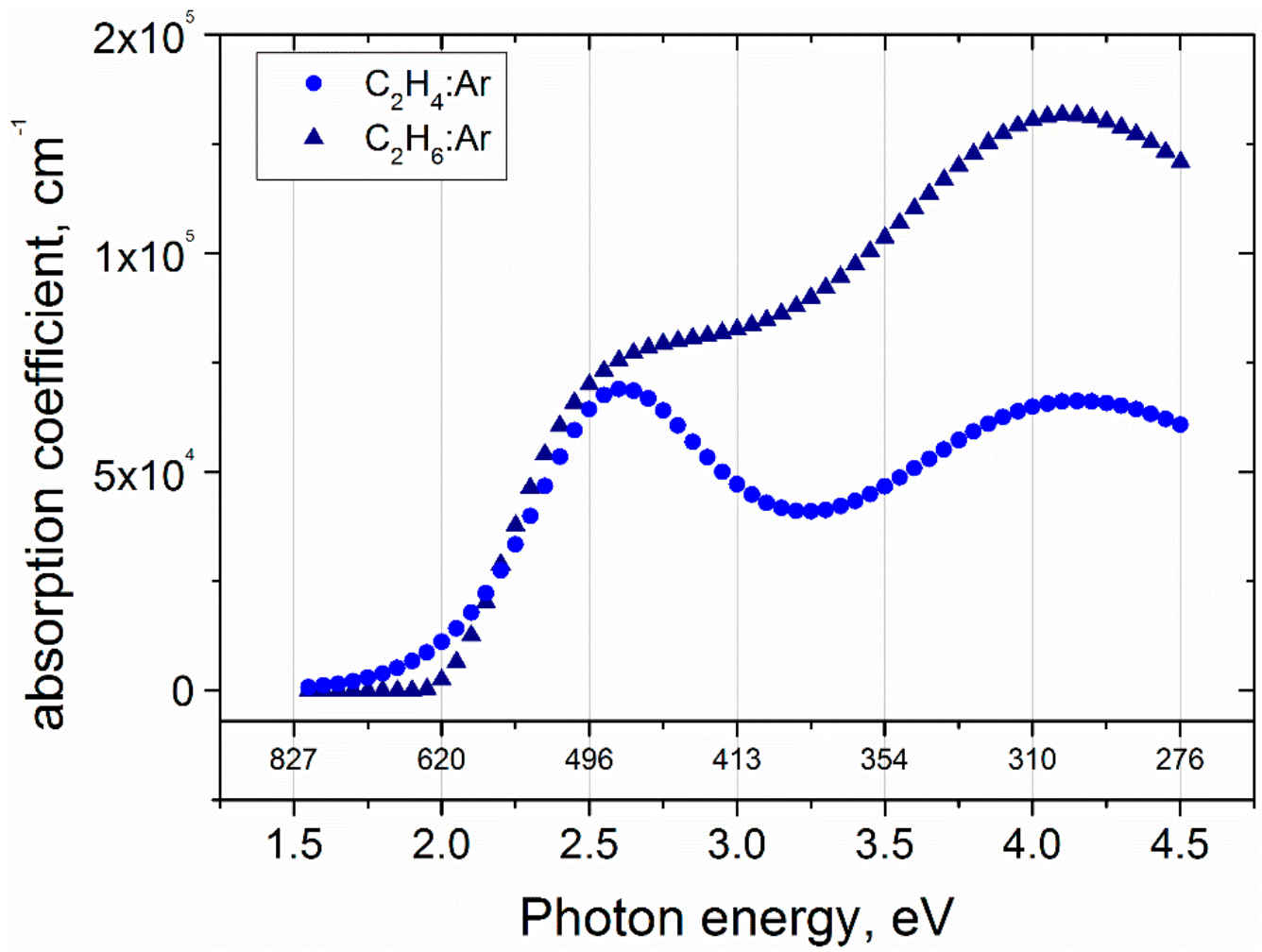

Figure 5. Absorption coefficients for the films prepared with $\mathrm{C}_{2} \mathrm{H}_{4} / \mathrm{Ar}$ and $\mathrm{C}_{2} \mathrm{H}_{6} / \mathrm{Ar}$ gas mixtures obtained from spectroscopic ellipsometry.

A systematic investigation of hydrogenated carbon films deposited with $\mathrm{CH}_{4}$ and $\mathrm{C}_{2} \mathrm{H}_{2}$ gas mixtures and employing different plasma deposition techniques has been carried out by Casiraghi et al. [6]. According to these studies, the optical band gap increases with increasing hydrogen content while at the same time the $I_{\mathrm{D}} / I_{\mathrm{G}}$ ratio decreases. Comparing our data with their results we can infer that the hydrogen contents of the present $\mathrm{C}_{2} \mathrm{H}_{4} / \mathrm{Ar}$ and $\mathrm{C}_{2} \mathrm{H}_{6} / \mathrm{Ar}$ films should be around $26 \%$ and $31 \%$, respectively. If correct, these values are close to the $\mathrm{H}$ content of hydrogenated tetrahedral carbon films which are intermediate between DLC and polymer-like films [6].

\section{Conclusions}

Amorphous hydrogenated carbon films were successfully deposited on Si (100) and aluminum coated glass substrates using a dielectric barrier discharge with $\mathrm{C}_{2} \mathrm{H}_{m} / \mathrm{Ar}(m=2,4,6)$ gas mixtures at a pressure of 300 mbar. Films show attractive and different yellow/brown colors which could be further tailored for use as decorative coatings. FT-IRRAS shows strong absorptions near $2900 \mathrm{~cm}^{-1}$ and at $1459 \mathrm{~cm}^{-1}$ and $1370 \mathrm{~cm}^{-1}$ which are related to $\mathrm{CH}_{2}$ and $\mathrm{CH}_{3}$ stretching and bending vibrations, respectively, of the $s p^{3}$ configuration. Some differences between the different gas mixtures are noted. The $\mathrm{C}_{2} \mathrm{H}_{6} /$ Ar film shows the strongest absorption near $2900 \mathrm{~cm}^{-1}$ and consequently the highest $s p^{3}$ $\mathrm{CH}_{3}$ bonding compared to the other two films. $\mathrm{C} \equiv \mathrm{C}$ functional groups are weak and only observed for the film from the $\mathrm{C}_{2} \mathrm{H}_{2} /$ Ar gas mixture. The presence of carboxyl groups is an indication that 
some post-deposition oxidation has occurred. Raman spectroscopy reveals the presence of D and G bands at 1643 and $1350 \mathrm{~cm}^{-1}$, respectively. The measured $\mathrm{I}_{\mathrm{D}} / \mathrm{I}_{\mathrm{G}}$ intensity ratio is 0.45 and 0.3 for the $\mathrm{C}_{2} \mathrm{H}_{4} / \mathrm{Ar}$ and $\mathrm{C}_{2} \mathrm{H}_{6} / \mathrm{Ar}$ films, respectively. An additional peak observed at $1460 \mathrm{~cm}^{-1}$ is assigned to the pentagonal pinch mode in trans-polyacetylene. Spectroscopic ellipsometry reveals that thin films obtained from $\mathrm{C}_{2} \mathrm{H}_{6} / \mathrm{Ar}$ and $\mathrm{C}_{2} \mathrm{H}_{4} / \mathrm{Ar}$ gas mixtures are characterized by a high refractive index of 2.81 and 3.07, respectively, at a photon energy of $2 \mathrm{eV}$. The extracted optical band gap is $1.91 \mathrm{eV}$ and $1.75 \mathrm{eV}$ for the $\mathrm{C}_{2} \mathrm{H}_{6} / \mathrm{Ar}$ and $\mathrm{C}_{2} \mathrm{H}_{4} / \mathrm{Ar}$ films. The observations are consistent with a significant hydrogen content of about $26 \%$ and $31 \%$ in the $\mathrm{C}_{2} \mathrm{H}_{4} / \mathrm{Ar}$ and $\mathrm{C}_{2} \mathrm{H}_{6} / \mathrm{Ar}$ films.

Acknowledgments: Part of this work was supported by the Deutsche Forschungsgemeinschaft (DFG) through Sonderforschungsbereich SFB/TRR24 "Fundamentals of Complex Plasmas", The International Max-Plank Research School (IMPRS) for "Bounded Plasmas" and through a Landesgraduiertenstipendium provided to one of us (HCT) by the University of Greifswald.

Author Contributions: The work constitutes part of Thejaswini's work. Thejaswini performed the measurement, contributed to the data analysis, and wrote the manuscript. Rainer Hippler was the supervisor and contributed to the writing of the manuscript and to the data analysis. Robert Bogdanowicz was responsible for the ellipsometry part. Eckart Rühl and Steffen Thierbach were responsible for Raman scattering, Vladimir Danilov and Jürgen Meichsner for the FTIR measurements.

Conflicts of Interest: The authors declare no conflict of interest.

\section{References}

1. Liu, A.Y.; Cohen, M.L. Prediction of New Low Compressibility Solids. Science 1989, 245, 841. [CrossRef] [PubMed]

2. Liu, A.Y.; Cohen, M.L. Structural properties and electronic structure of low-compressibility materials: $\beta-\mathrm{Si}_{3} \mathrm{~N}_{4}$ and hypothetical $\beta-\mathrm{C}_{3} \mathrm{~N}_{4}$. Phys. Rev. B 1990, 41, 10727. [CrossRef]

3. Rodil, S.E.; Ferrari, A.C.; Robertson, J.; Muhl, S. Infrared spectra of carbon nitride films. Thin Solid Films 2002, 420, 122. [CrossRef]

4. Thejaswini, H.C.; Hoskinson, A.R.; Agasanapura, B.; Grunde, M.; Hopwood, J. Deposition and characterization of diamond-like carbon films by microwave resonator microplasma at one atmosphere. Diam. Rel. Mater. 2014, 48, 24. [CrossRef]

5. Pothiraja, R.; Bibinov, N.; Awakowicz, P. Plasma-Chemical Kinetics of Film Deposition in Argon-Methane and Argon-Acetylene Mixtures under Atmospheric Pressure Conditions. In Chemical Kinetics; Patel, V., Ed.; InTech: Rijeka, Croatia, 2012; Chapter 11; Available online: http:/ / www.intechopen.com/books/chemical-kinetics/plasma-chemical-kinetics-of-film-deposition-inargonmethane-and-argon-acetylene-mixtures-under-atmo (accessed on 21 April 2016).

6. Casiraghi, C.; Piazza, F.; Ferrari, A.C.; Grambole, D.; Robertson, J. Bonding in hydrogenated diamond-like carbon by Raman spectroscopy. Diam. Rel. Mater. 2005, 14, 1098. [CrossRef]

7. Cui, F.Z.; Qing, X.L.; Zhao, J. Biomedical investigations on $\mathrm{CN}_{\mathrm{x}}$ coating. Surf. Coat. Technol. 2005, $200,1009$. [CrossRef]

8. Kato, K.; Koide, H.; Umehara, N. Micro-wear properties of carbon nitride coatings. Wear 2000, $238,40$. [CrossRef]

9. Godet, C.; Adamopoulos, G.; Kumar, S.; Katsuno, T. Optical and electronic properties of plasma-deposited hydrogenated amorphous carbon nitride and carbon oxide films. Thin Solid Films 2005, 482, 24. [CrossRef]

10. Godet, C.; Kleider, J.P.; Gudovskikh, A.S. Scaling analysis of field-enhanced bandtail hopping transport in amorphous carbon nitride. Phys. Status Solidi B 2007, 244, 2081. [CrossRef]

11. Kumar, A.; Srivastava, A.; Galaev, I.Y.; Mattiasson, B. Smart polymers: Physical forms and bioengineering applications. Prog. Polym. Sci. 2007, 32, 1205-1237. [CrossRef]

12. Pucci, A.; Ruggeri, G.; Bronco, S.; Signori, F.; Donati, F.; Bernabo, M.; Ciardelli, F. Colour responsive smart polymers and biopolymers films through nanodispersion of organic chromophores and metal particles. Prog. Org. Coat. 2011, 72, 21-25. [CrossRef]

13. Kim, S.Y.; Kim, H.S.; Augustine, S.; Kang, J.K. Nanopores in carbon nitride nanotubes: Reversible hydrogen storage sites. Appl. Phys. Lett. 2006, 89, 253119. [CrossRef] 
14. Zhang, Y.; Zhou, Z.; Li, H. Crystalline carbon nitride films formation by chemical vapor deposition. Appl. Phys. Lett. 1996, 68, 634. [CrossRef]

15. Li, Y.; Zhang, S.; Liu, Y.; Chen, T.P.; Sritharan, T.; Xu, C. Magnetron sputtered nc- $\mathrm{Al} / \alpha-\mathrm{Al}_{2} \mathrm{O}_{3}$ nanocomposite thin films for nonvolatile memory application. J. Nanosci. Nanotech. 2009, 9, 4116. [CrossRef]

16. Wu, D.; Fu, D.J.; Guo, H.; Zhang, Z.; Meng, X.; Fan, X. Structure and characteristics of $\mathrm{C}_{3} \mathrm{~N}_{4}$ thin films prepared by rf plasma-enhanced chemical vapor deposition. Phys. Rev. B 1997, 56, 4949.

17. Merel, P.; Chaker, M.; Tabbal, M.; Moisan, M. The influence of atomic nitrogen flux on the composition of carbon nitride thin films. Appl. Phys. Lett. 1997, 71, 3814. [CrossRef]

18. Reitz, U.; Salge, J.G.H.; Schwarz, R. Pulsed barrier discharges for thin film production at atmospheric pressure. Surf. Coat. Technol. 1993, 59, 144. [CrossRef]

19. Goossens, O.; Dekempeneer, E.; Vangeneugden, D.; van de Leest, R.; Leys, C. Application of atmospheric pressure dielectric barrier discharges in deposition, cleaning and activation. Surf. Coat. Technol. 2001, 142-144, 474. [CrossRef]

20. Massines, F.; Sarra-Bournet, C.; Fanelli, F.; Naude, N.; Gherardi, N. Atmospheric Pressure Low Temperature Direct Plasma Technology: Status and Challenges for Thin Film Deposition. Plasma Process. Polym. 2012, 9, 1041. [CrossRef]

21. Kogelschatz, U. Dielectric-Barrier Discharges: Their History, Discharge Physics, and Industrial Applications. Plasma Chem. Plasma Process. 2003, 23, 1. [CrossRef]

22. Thejaswini, H.C.; Peglow, S.; Martens, U.; Sushkov, V.; Hippler, R. Comparative Plasma Chemical Reaction Studies of $\mathrm{CH}_{4} / \mathrm{Ar}$ and $\mathrm{C}_{2} \mathrm{H}_{m} / \mathrm{Ar}(m=2,4,6)$ Gas Mixtures in a Dielectric Barrier Discharge. Contrib. Plasma Phys. 2014, 54, 683-696. [CrossRef]

23. Thejaswini, H.C.; Majumdar, A.; Tun, T.M.; Hippler, R. Plasma chemical reactions in $\mathrm{C}_{2} \mathrm{H}_{2} / \mathrm{N}_{2}, \mathrm{C}_{2} \mathrm{H}_{4} / \mathrm{N}_{2}$, and $\mathrm{C}_{2} \mathrm{H}_{6} / \mathrm{N}_{2}$ gas mixtures of a laboratory dielectric barrier discharge. Adv. Space Res. 2011, $48,857$. [CrossRef]

24. Majumdar, A.; Behnke, J.F.; Hippler, R.; Matyash, K.; Schneider, R. Chemical Reaction Studies in $\mathrm{CH}_{4} / \mathrm{Ar}$ and $\mathrm{CH}_{4} / \mathrm{N}_{2}$ Gas Mixtures of a Dielectric Barrier Discharge. J. Phys. Chem. A 2005, 109, 9371. [CrossRef] [PubMed]

25. Majumdar, A.; Hippler, R. Development of dielectric barrier discharge plasma processing apparatus for mass spectrometry and thin film deposition. Rev. Sci. Instr. 2007, 78, 075103. [CrossRef] [PubMed]

26. Martens, U.; Thejaswini, H.C.; Majumdar, A.; Hippler, R. Deposition of Amorphous Hydrogenated Carbon Nitride Films with a Dielectric Barrier Discharge. Plasma Proc. Polym. 2012, 9, 647. [CrossRef]

27. Shirakura, A.; Nakaya, M.; Koga, Y.; Kodama, H.; Hasebe, T.; Suzuki, T. Diamond-like carbon films for PET bottles and medical applications. Thin Solid Films 2006, 494, 84-91. [CrossRef]

28. Girard, H.A.; Arnault, J.C.; Perruchas, S.; Saada, S.; Gacoin, T.; Boilot, J.P.; Bergonozo, P. Hydrogenation of nanodiamonds using MPCVD: A new route toward organic functionalization. Diam. Rel. Mater. 2010, 19, 1117-1123. [CrossRef]

29. Robertson, J. Diamond-like amorphous carbon. Mater. Sci. Eng. R 2002, 37, 129. [CrossRef]

30. Lazar, G.; Zellama, K.; Vascan, I.; Stamate, M.; Lazar, I.; Rusu, I. Infrared absorption properties of amorphous carbon films. J. Optoelectron. Adv. Mater. 2005, 7, 647.

31. Stan, G.E.; Marcov, D.A.; Popa, A.C.; Husanu, M.A. Polymer-like and diamond-like carbon coatings prepared by RF-PECVD for biomedical applications. Dig. J. Nanaomater. Biostruct. 2010, 5, 705.

32. Bian, X.; Chen, Q.; Zhang, Y.; Sang, L.; Tang, W. Deposition of nano-diamond-like carbon films by an atmospheric pressure plasma gun and diagnostic by optical emission spectrum on the process. Surf. Coat. Tech. 2008, 202, 5383. [CrossRef]

33. Li, H.; Xu, T.; Wang, C.; Chen, J.; Zhou, H.; Liu, H. Annealing effect on the structure, mechanical and tribological properties of hydrogenated diamond-like carbon films. Thin Solid Films 2006, 515, 2153. [CrossRef]

34. Bugaev, S.P.; Korotaev, A.D.; Oskomov, K.V.; Sochugov, N.S. a-C:H films deposited in the plasma of barrier and surface discharges at atmospheric pressure. Surf. Coat. Tech. 1997, 96, 123. [CrossRef]

35. Thejaswini, H.C.; Bogdanowicz, R.; Schaefer, J.; Danilov, V.; Meichsner, J.; Hippler, R. Deposition and characterization of organic polymer thin films using a dielectric barrier discharge with different $\mathrm{C}_{2} \mathrm{H}_{m} / \mathrm{N}_{2}$ ( $m=2,4,6)$ gas mixtures. Eur. Phys. J. D 2015, 69, 142. 
36. Hobert, H.; Dunken, H.H.; Meinschien, J.; Stafast, H. Infrared and Raman spectroscopic investigation of thin films of AlN and SiC on Si substrates. Vib. Spectrosc. 1999, 19, 205. [CrossRef]

37. Musa, G.; Vladoiu, R.; Ciupina, V.; Janik, J. Raman spectra of carbon thin films. J. Optoelectron. Adv. Mater. 2006, 8, 621 .

38. Marcinauskas, L.; Grigonis, A.; Valincius, V.; Valatkevicius, P. Surface and Structural Analysis of Carbon Coatings Produced by Plasma Jet CVD. Mater. Sci. 2007, 13, 269.

39. Oliveira, É.C.; Cruz, S.A.; Aguiar, P.H.L. Effect of PECVD deposition parameters on the DLC/PLC composition of a-C:H thin films. J. Braz. Chem. Soc. 2012, 23, 1657. [CrossRef]

40. Gioti, M.; Papadimitriou, D.; Logothetidis, S. Optical properties and new vibrational modes in carbon films. Diam. Rel. Mater. 2000, 9, 741. [CrossRef]

41. Logothetidis, S.; Gioti, M.; Patsalas, P.; Charitidis, C. Insights on the deposition mechanism of sputtered amorphous carbon films. Carbon 1999, 37, 765. [CrossRef]

42. Gioti, M.; Logothetidis, S. Dielectric function, electronic properties and optical constants of amorphous carbon and carbon nitride films. Diam. Rel. Mater. 2003, 12, 957. [CrossRef]

43. Jellison, G.E.; Modine, F.A. Parameterization of the optical functions of amorphous materials in the interband region. Appl. Phys. Lett. 1996, 69, 371. [CrossRef]

44. Palik, E.D. Handbook of Optical Constants of Solids II; Academic Press: San Diego, CA, USA, 1991.

45. Tompkins, H.G.; Irene, E.A. Handbook of Ellipsometry; William Andrew: Norwich, UK, 2005.

46. Benmassaoud, A.A.; Paynter, R.W. Influence of the power and pressure on the growth rate and refractive index of a-C:H thin films deposited by r.f. plasma-enhanced chemical vapour deposition. Thin Solid Films 1996, 287, 125-129. [CrossRef]

47. Hong, J.; Goullet, A.; Turban, G. Ellipsometry and Raman study on hydrogenated amorphous carbon (a-C:H) films deposited in a dual ECR-r.f. plasma. Thin Solid Films 1999, 352, 41-48. [CrossRef]

48. Tolmachiev, V.A.; Konshina, E.A. Ellipsometric study of a-C:H films. Diam. Relat. Mater. 1996, 5, $1397-1401$. [CrossRef]

49. Zaharia, T.; Sullivan, J.L.; Saied, S.O.; Bosch, R.C.M.; Bijker, M.D. Fast deposition of diamond-like hydrogenated carbon films. Diam. Relat. Mater. 2007, 16, 623-629. [CrossRef]

50. Xu, S.; Tay, B.K.; Tan, H.S.; Zhong, L.; Tu, Y.Q.; Silva, S.R.P.; Milne, W.I. Properties of carbon ion deposited tetrahedral amorphous carbon films as a function of ion energy. J. Appl. Phys. 1996, 79, 7234-7240. [CrossRef]

51. Tauc, J.; Abelès, F. The Optical Properties of Solids; Academic Press: New York, NY, USA, 1972. 